\title{
Transatlantica
}

Revue d'études américaines. American Studies Journal

Cartographies de l'Amérique / Histoires d'esclaves

\section{An Interview with Rob Stephenson}

\section{Anne-Laure Tissut}

\section{(2) OpenEdition}

\section{Journals}

Édition électronique

URL : https://journals.openedition.org/transatlantica/6066

DOI : $10.4000 /$ transatlantica.6066

ISSN : 1765-2766

Éditeur

Association française d'Etudes Américaines (AFEA)

Référence électronique

Anne-Laure Tissut, «An Interview with Rob Stephenson», Transatlantica [En ligne], 2 | 2012, mis en ligne le 21 juin 2013, consulté le 06 avril 2023. URL : http://journals.openedition.org/transatlantica/ 6066 ; DOI : https://doi.org/10.4000/transatlantica.6066

Ce document a été généré automatiquement le 6 avril 2023.

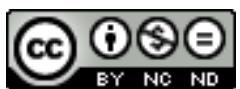

Creative Commons - Attribution - Pas d'Utilisation Commerciale - Pas de Modification 4.0 International - CC BY-NC-ND 4.0

https://creativecommons.org/licenses/by-nc-nd/4.0/ 


\section{An Interview with Rob Stephenson}

\section{Anne-Laure Tissut}

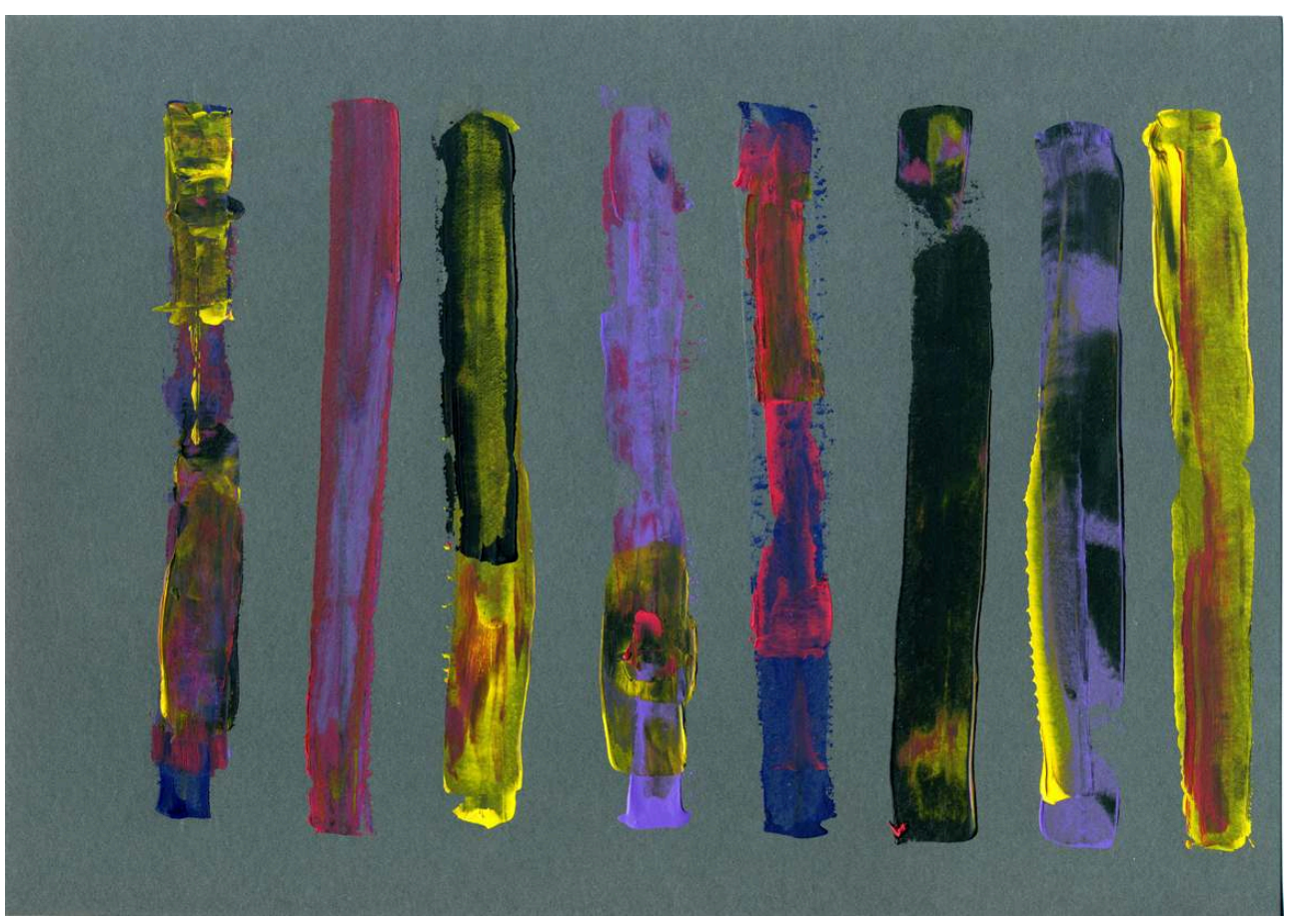

\section{Interview}

Rob Stephenson is an author, composer, visual artist living in Queens, NY. He has been creating texts, music, video, films, drawings, paintings, and installations for over thirty years. He has a BA in Experimental and Interdisciplinary Art from San Francisco State University and an MFA in Electronic Media from Mills College. He is the author of Passes Through (FC2/University of Alabama Press) and frequently publishes in journals and anthologies. He received an outstanding achievement award from The Center For Experimental and Interdisciplinary Art. His drawings have been exhibited at Intersection For The Arts in San Francisco, The Headlands Center for the Arts, The 
Katona Museum, and the Wexler Center For The Arts. His film, music, and video projects have been presented at Cinematheque and The Lab in San Francisco, The Eye Music Festival in Seoul, Korea, Haven Arts, Bronx, NY, Galapagos in Brooklyn. NY, Dixon Place and The Stone in NYC, The \& NOW Festival in Buffalo, NY and The Oracle Club in LIC.

2 He also is a pianist and a composer. The CD dog by Mikael Karlsson and Rob Stephenson, released in 2006 is an eclectic collection that fuses contemporary classical composition, improvisation, musique concrète, spoken word, and a variety of electronic techniques.

Rob and I met at the FC2 Writers' Edge Creative Writing Seminar held in Portland, Oregon in July 2008. Soon we launched into long talks about art and life. Rob had drawn the FC2 board's attention with Passes Through, his novel then yet-to-be-published. He did me the favour of entrusting me with the typescript. I read it on the plane on the way back to Paris. What a flight. Never had I read a literary work by someone I knew without projecting their face, character and idiosyncrasies, upon the text. Although originating from Rob's journals, a complex collage of sorts, Passes Through let such a diversity of voices arise that its author's got lost in the vast choir of perceptions, thoughts and feelings that made up the life of his artistic consciousness. His voice was to be heard though, later at the Shakespeare\&Co bookstore on Paris embankments, for the reading he gave of Passes Through, in which I also took part. A few months later, Rob favored the Sorbonne English Department with a talk that thrilled the students. We all had the clear sense that so much had been said and so much left unsaid for the stupid reason of lack of time. The idea of the interview arose from that meeting, to give us all a chance to hear more from Rob.

Anne-Laure Tissut: Passes Through is an unconventional novel that carries the reader along the meanderings of the character's thoughts, making up a poetic meditation on creation. It also offers an intense rendering of the emotions and sensations of living, and more precisely, conveys the powerful effects that language has upon the persona: "It is here where everything seems to flow that opposed ideas dash in silence. I long for eyes that can see what language does to me." (135)

As a visual artist, a music composer and a writer, do you have a vision of the musical or other effects of language on you? Are they the effects that you aim at passing on to the readers?

Rob Stephenson: I am aware that my own state of mind at every moment influences very much how I receive and make meaning out of visual, aural, and written messages. I enjoy repeated exposure to specific things over time to allow for the understanding of many possible ways they could be affecting me. I hope that a cumulative effect of how I've thought about language over the years is passed on to readers.

Much of what I do is involved in ideas about making music, so in dealing with words, I tend to care very much about how they sound and consider the sound itself to influence what a text means. When learning a foreign language (I have been studying German for many years now), the sound and pacing of conversation can assist greatly in knowing what is being said, even if some meaning is unclear or unknown. For better and sometimes worse, these gaps are filled in partially by the underlying rhythms inherent in the language. So I would have to say that considering how a text sounds is as important to me as how it appears. I have played with the idea, as well, that the sound of a text could be made to rub against the more concrete aspects of 
meaning inherent in what is written, even as it is being read silently from the page or the screen.

AT: The persona in Passes Through states his intention of "mak[ing] a talking diary." (67) It has a confessional tone to it, likely to further involve the reader, yet the address never explicitly stages a "you": it is not a dialogue, and what might look like a monologue at first sight actually illustrates Bakhtin's heteroglossia as much as any novel. "I wanted the individual voices to run on and on until they found something no individual voice knew was there" (this is the persona speaking) (55). The persona's or speaker's consciousness is pervaded by a profusion of language of the most diverse origins: artistic discourses, slogans seen in the street, comments on artworks, graffiti written on murals or bits of conversation heard.

Given such diversity and the use of the first person, what is the reader's stance: is she more involved than in drama? Is she more than an audience or a witness? How did you conceive of the reader's stance or role in your novel?

RS: Passes Through is a very open text in the sense that the reader must participate in reconstructing a specific meaning for herself. Every novel is like that at least a little bit, but my novel requires an active participation towards extrapolating meaning from a rather abstract field of potentially connective material. Words and phrases can relate to one another in a complex mapping of corollaries across the entire text.

My narrator, who can be described as a cluster of personas, doesn't have many answers and has conflicting answers when he does. I never had any certain ideas about how a particular anonymous reader would remake Passes Through in her mind. I expected few would enter it to that degree and have been amazed at how so many different readers have discovered such a variety of things to like about the book.

I did want to make the text enjoyable to read and to hear, but the text craves an active reader, an innovative interpreter who wants to discover what I am trying to do and make the novel with me. I think one has to learn how to read this book in a way that reflects how I learned to write it. I refused to drag readers through the text as if by pulling on chains hooked through their noses.

AT: Although this first novel, Passes Through, was born out of the diaries that you kept for many years, it is a novel indeed and obviously by calling it that you are not simply catering to the commercial needs of booksellers who like to know where to put the book on their shelves-and the customers to be able to locate them. Which are the main characteristics that make a novel of Passes Through? How did you work on it as a novel?

RS: Some have said this book is a long poem and not a novel. I can agree that is it a poem and I claim it is a musical composition as much as it is a novel. I thought of it as many things simultaneously during the time I made it. Part of the reason I made it was as an attempt to remove or revise the boundaries between many forms.

In general I find it more rewarding to talk about what something could be rather than what it must be. But simply put, Passes Through is a musical composition made of written images.

My self-conscious refusal to settle into the kind of things novels usually do in order to become a novel and my insistence on speaking about this literally and figuratively as the text meanders, digresses, leaps over huge voids of erasure, all the while accumulating incrementally into complexity indicates that I am seeking another way to make a novel. The entire thing is made out of things already written, so it is reasonable to look at what I have done to the language as well as with the language. 
AT: In Passes Through, there is an adequation in time between our reading and the persona's thoughts that we are supposed to follow. For that matter, your novel may remind one of the stream of consciousness technique. Yet it seems to be doing a different thing with language and structure, not so much attempting at reproducing the mind's wanderings as giving them, or shaping them into, a structure that they could never have had. Such structure relies on repetitions and motifs or patterns, as well as on silence, as their necessary counterpart.

Did you intend to offer an experience of /in time in Passes Through, as its title may be thought to indicate? Or more generally was time part of the conceptual dimension of your project?

RS: Through the study of music I encountered many concepts of time from all over the world. I deciphered intricate shifting rhythmic patterns of music from around the world: from African Pygmy "chorales" and Indian tala, to the orchestrations of Indonesian gamelon, Japanese gagaku, Persian classical music, etc. I began to see in a very particular way that time isn't limited to a single cultural definition or expression. It is experienced in many, many different regards all over the world.

The passing of time is to me to be a very intricate affair, varying from person to person especially across language and cultural divides. Eventually, my interest in time became linked to the study of memory and how memory shapes consciousness, which is inevitably part of what determines how people experience time. All of this became part of the impetus to make Passes Through.

So to answer your question a bit more specifically, there is awareness of how stream of consciousness writing operates in Passes Through; however, my methods for remaking already existing writing are procedural, based in translating musical ideas and visual forms into a literary format and guided by regulations that allow freedoms. It could be said that I plan spontaneity; you could even say that I make plans to get lost in a tangle of constantly partitioning thought reconstruction.

AT: In Passes Through, you seem to have developed a deliberate strategy of complexifying the character, that makes for a highly flexible relation between persona and reader, that illustrates if not exacerbates the infinite variety of possible readings of a novel-of any novel, but of this one, to a higher degree because of its highly allusive and elusive quality. Could you tell us more about this process of complexifying?

RS: The complexity in the composition of Passes Through is much more elaborate than the final text may indicate. It is not important for the reader to know that, but it might be interesting to some. I used extensive destructive techniques to the degree that a typical sounding/meaning sentence can be made up from many different sources.

I worked both with rewriting by hand on paper as well as using the computer to type my text. I think differently when I write with a pencil or pen (a drawing activity) than when I type on a keyboard (a percussive activity). There were some very odd collisions of these methods.

In most novels the narrator or main character has some basic certainties about where he is and how he is moving through the book. In Passes Through the narrator is not sure about much of anything. He doesn't know where he is in the physical world, there is no division between where he has been and everything that goes on around him. Internal and external worlds are indiscrete. The thoughts expressed are conglomerations of voices he encounters and has encountered. He is stuck in a 
distorted past that is a vast middle posing as a present. The narrator does end up having something of a singular voice even though he is made up of so many different ones from so many different times and spaces. This proliferation of voices does complicate how original meanings are ruptured and rewoven together in the text.

AT: Would you think of yourself as composing a field of changing intensities when writing?

RS: Especially in Passes Through this is an intention.

AT: Because Passes Through so much relies on the non-said, the readers' active participation is far more required than in a more conventionally written novel, as she has to imagine the underlying text, or to invent the missing links, while paying attention to the resonance of words throughout the book. How did you negotiate the balance to be maintained between allusiveness and the measure of continuity without which the reader fails to be made able to follow the persona's speech?

RS: I have spent a lifetime seeking out and absorbing all manner of formal perspectives across many media. I have been diligent at studying forms and patterns and contemplating how they do certain things. I expected this decade-long attentiveness to facilitate my ability to do what was necessary to make Passes Through cohesive.

I wrote it for the reader who wanted something to return to again and again, something that wouldn't be the same each time. And yes, any novel is different every time, of course, because the reader changes always; however, I tried to create a situation in this text where an intentionally generated openness allows for multiple kinds of connectability. The level of abstraction and stasis of a mind not directed towards specific tasks is presented in contrast to the inevitable bleed through of traditional storytelling logic.

I have thought about these matters for years and identified them in art and elsewhere. Though the text sources and fragments have no relation in their ordering to the time and space in which they came to be, I assembled this text from beginning to end literally to insure a kind of linearity, one that hangs together I hope, but in a much different way than in most novels.

In spite of the formal, structural, and systematic concerns of Passes Through and my attempt to transform whatever is autobiographical, I very much wanted to bring to the text some sense of the emotional extremes of life lived during the period I kept the journal. I shunned any tendency towards event-by-event accuracy in relaying what happened during that time in the hopes of conveying instead an essence rooted in the qualities of living those years.

There is a withholding in the book that does imply an underlying text, a constant referring to something that isn't quite there or is everywhere so dispersed that it is haunted by the atomized particles of itself and many other texts connected in fleeting, easily unrecognizable configurations. The absent text may be the autobiographically sound novel, a truly Impossible Object (I misuse here an idea from non-Euclidean geometry by way of Nicholas Mosley) Passes Through refuses to be, yet can't help alluding to incessantly in cryptic ways.

AT: What are the interactions between composing music and writing?

RS: One small answer to that enormous question is Passes Through. 
There isn't one enormous answer, although I give some partial answers all along the way in this interview. It will take a large number of authors/composers to create and expand on the possible interactions, artists who are willing to spend time hybridizing these two (or more) worlds of making.

I consider myself fortunate to have been part of one of the two interdisciplinary art undergraduate/graduate programs that flourished for a brief time in the mid-80s in the U.S. There was one at CUNY in Purchase New York and I attended the one at San Francisco State University, the Center For Experimental and Interdisciplinary Art (CEIA).

Students from all art disciplines worked together in interdisciplinary classes. We were asked to invent projects across artistic media and incorporate material from classes of any sort: science, history, sociology, math, philosophy, whatever. The idea was to consider everything in the university as part of the artist's palette. The Center was a bit like a mini-Bauhaus octopus in the middle of a huge university setting, sending out tentacles into every field of study.

The video artist Ellen Zweig was a major force in the CEIA program: designing classes, advising students in the creation and implementation of elaborate independent and collaborative projects.

I had many memorable teachers: Sharon Girard (three years studying the music of Africa and Asia), Robert Bell (film theory), Leslie Thornton (filmmaking), Nanos Valoritis (literature), Bill and Mary Buchen (sound sculpture), and Herbert Bielawa (electronic music studio) to name just a few in art related fields.

This environment suited me. I had already studied willy-nilly at four different colleges before I landed in this program, so I was quite good at finding teachers I enjoyed, no matter what subject matter they taught. Out of all my random college hopping, I developed a perverse post-adolescent Montessori type approach for subverting restrictive school programs. I learned from so many different kinds of teachers in such diverse situations. I continue to do so. Perhaps everyone can teach you something depending on your attitude.

I worked in the SFSU library and spent part of that time browsing and reading the art, literature, film, music books and journals. I was very fond of the experimental psychology section.

A significant portion of my education has come from exploring libraries. I use quite a lot of them here in New York City in addition to the public library systems. There is something so marvellous about wandering in an architecture filled with shelves and shelves of books. There is also something marvellous about having a cloud of data at hand wherever one is in the world, but the two experiences are not the same. So far there is lingering uneasiness towards the notion that the inevitable cloud will replace the physical houses filled with easily accessible book objects.

As a child I always wrote poetry, essays, stories, while composing, playing the piano. I drew, made collages. But I toyed with technology, too. I played with cameras and tape recorders. I tried all sorts of mechanical things to get an idea of how they worked. 
People don't have to give up multiple creative activities as they age. The traditional assessment of worth in creative endeavours is very much stilted towards expertise in a single medium.

I could not have made Passes Through without continual practice in many mediums.

AT: Can the novel be seen as a script of sorts? Would you improvise while reading it, or is the text rather a score, that you interpret with various emotions and feelings, like a musician, but without changing the notes, so to speak?

RS: I never read from the book the same way. I change speeds, I jump around to different sections sometimes. I make a specific miniature text for every performance. It keeps me interested, on my toes, and makes me consider things about the text differently every time I come to it, which again is what I ask of a reader.

In a way Passes Through is the result of a score. Scoring has figured in much of my work over the years. A musical score exists to make someone play a music they could not and would not play without it.

In the eighties I made several short films by using frame by frame scoring techniques and I used to make what I call after-scores to densely hyperactive electronic music compositions: precise as possible graphic diagrams of the electro-acoustic soundscapes of Karlheinz Stockhausen, Pierre Henry, Arne Nordheim, Pierre Schaeffer. I listened to small portions of their pieces over and over again until I could sketch representative images onto graphs with time and pitch indications. To this day, even though by now there must be a phone app that can do it for me, I enjoy listening carefully to the passing of time in diverse environments and imagining correlating imagery.

Such are the exergues at the beginning of Part 3 (59), "Ja, Mehr: la mer"?

Quoting gets on my nerves. But we are sequestered in a world that is constantly quoting, in a constant quotation that is the world...

\section{Thomas Bernhard - Gargoyles}

... every piece you put in fits, and then when you finish it, you see that it's not the picture. Then you do another version and it's not the picture. Finally you realize you are not going to get a picture.

Morton Feldman - Give My regards to Eighth Street

... perhaps it's the sea that never leaves them alone, that's always there making a noise ...

Marguerite Duras- Blue Eyes. Black Hair.

AT: Could you tell us more about them? What do these words and artists mean to you?

RS: In his youth, Thomas Bernhard was a singer, but due to illness, had to channel all of his love of music into making the German language operatic on the page. I was attracted early on to the unsettling spiral monologues in his novels, which are basically elegant and disturbing critical probes into philosophical mires. They are wryly scathing and every so often, hilariously dire. And they breathe, sometimes rasping.

From Frost through Extinction he never misses a stroke. His circular repetitions conjure up more shades of black than a retrospective of Ad Reinhart paintings. He 
remakes his own methods every time and they are to me completely compelling as they slowly uncoil, revealing multiple perspectives.

Marguerite Duras' lifelong determination to blur the boundaries between novel/ play/film (Le Camion is a wonderful example) mirrors my attempt to fuse music, writing, and visual art inside a textual field in Passes Through. As well, the ravished body of Duras' work can be seen as a painfully drawn-out languishing examination of desire in a fictionally autobiographical sense. This is one prerequisite for the process of repeatedly passing through my journal to write the text of Passes Through. No one revisits ideas over time quite the way Duras does, either in the course of one work or in the course of a lifetime.

Morton Feldman sits between these writers on the page. He is the colon: the gobetween, the in-between, and the connector between them in that section of Passes Through.

Feldman pursued a level of abstraction imbued with intense eluding loveliness by crumbling many pillars of traditional musical structures into a Trümmerfeld (an expanse of rubble). He re-used tiny bits of musical material by distributing them across time via various open field systems, initially using graph paper to chart his processes and finally in his last years by recognizing the patterns that appear in the minute fluctuations in ancient hand-woven carpets from around the world.

The quotations from these artists suggest three very contrary ways to look at what a world can be. Passes Through moves through many worlds in order to make its own.

What I've just said above about these three artists doesn't at all do their creations justice. I have offered painfully reduced approximations of things that relate to my text. I not only admire their art, but I have luxuriated in each of their unique flavours of stubbornness.

AT: You seem to be moved by an unquenchable thirst for culture in all forms and genres. How would you describe the uses you make of all the culture that you have been absorbing? How do you appropriate it or recycle it?

RS: As far as ideas that come and go, I like to imagine that I don't appropriate as much as I recognize relationships between what I do in all sorts of unlikely places and that the ideas I employ are then amplified and reinforced as a result. If you want to call that appropriation, then I am guilty.

I enjoy the idea that certain ideas are mine, even though there is good evidence that nobody's ideas are their own. They all come from somewhere else, don't they? People are just better or worse at synthesizing them into unique potentials.

After the publication of Passes Through I thought in a different way about how I bring things together, because, like you, others were asking me about this and I felt like I should have an answer. All manner of material comes through me and I develop ways to sift and sort and filter the sea of information. When Ben Marcus says "read everything you can get your hands on" I can agree with that at times: cereal boxes and smut and liner notes and medical research documents and senate hearings and badly translated instructions for assembling furniture and catalogues about plastic objects and wills and hymnals and math tests and well-I enjoy theory. 
I've always been a promiscuous reader. I have a developed capacity for absorbing material from the world and the gregarious curiosity to keep doing it. That's why I like to live in big cities and travel.

As far as specific text is concerned, I do use found text and have for over thirty years at various times. My methods of using found text originally came from an interest in Burroughs, the Situationists, and the Dadaists. There was some valuable encouragement around that time from Janis Lipzin, a wonderful artist who at that time taught film and photography at the San Francisco Art Institute. She urged me to continue exploring the use of found materials, she introduced me to Duras' film India Song and later to Martin Heidegger by passing on to me an article about how artists use concepts of time.

In more recent years, something else has developed in how I work and this comes out of the way I breakdown and rebuild text using musical models. Mostly I alter found text so much that it becomes something other than the original text anyway, often something opposed to or deviating away from the source context. It ceases to be quotation by the time I am finished with it.

In Passes Through, tiny bits of many other texts are mixed with my own until the two types are for the most part indistinguishable. The references to pre-existing writings are (dis)allusions more often than not. Passes Through is full of these cock-ups of my original journal and readymade texts. It's totally bent, queered, and ass-backward. All of the "ands" and "buts" in the text come from different places. Not quite that, but something like that is going on.

Recently, I have been reading the writings of Severo Sarday. The English translations by Suzanne Jill Levine and Carol Meier are radiance singing. The writing is so different from mine, yet I find in the texts a coaxial queering in relation to my own, a perverting via (mis)quotation. His idea of imperfect simulation has kinship to what I was doing in Passes Through. I developed many ways to extend the unavoidable mistakes of copying by aping examples found in technology, visual art, and critical theory.

As I read Sarday, I feel his flamboyant flair for theoretical lyricism settling over my own text like an out of phase makeover.

In the decade before making Passes Through I published several essays that were autobiographical alongside disturbing erotic/pornotopian fictions, all much more based in the idea of a unified narrative voice, but sometimes tending towards fragmentation and disruption of the singular voice. A current example of the latter appears in the anthology, Dirty: Dirty, recently out from Debra DiBlasi's Jaded Ibis Press.

With Passes Through, I wanted to make a much longer fictional form, emphasizing, reshaping the methodologies of my aural and visual artworks applied to the written recording of a long period of my life, an exhaustive journal I had finally abandoned and had never thought to publish.

I've always been drawn to extremes of expression as long as they strove towards emotional intelligence. Bernhard and Duras created fantastic negating, abject fusions of emotional and political extremes, so very different from one another. 
Alongside an interest in that kind of art, there has been equal interest in visual and sonic abstraction, sometimes of a very formal level of organization, systems that operated in a cooler, removed, more distant manner. The mathematical, the technical, the systemic, these things are present in what I make, but not ends in themselves.

Passes Through is a tug-of-war between these two (at least) modes or a friction between them. Though in this interview and others, I speak about formal elements most of the time (that is what the questions are usually about that I get and it is easier for me to speak about that kind of thing. Some things just have to speak for themselves in the work.), it must be said that I wanted Passes Through to be vital. I wanted the urgency of transgressive whimsy to glitter through the text. I wanted rampant vibrant contradiction to emerge aesthetically. Abandon tempered with restraint. The hideously beautiful. A whole world reflected in ten thousand cracked and warped mirrors. Nothing exactly as it was and only what it can be when it has been pulled apart and put back together again. The glorious inconsistency of the Hydra-self, the We-Are-Legion self. Consistency and certainty are not absent in Passes Through, they are dislocated. They are everywhere other. They are inscribed in movement. The consistency is in how a cluster of inconsistencies bundle together: a quest for re-meaning through the extremes of oppositions that collect around nodes in an elaborate network of textual Humpty-Dumptiness: the fractured iterations, the futile attempts by all the king's horses and all the king's men to put poor H-D back together again. Rows and rows of endless variation obscuring the idea of the original into irretrievability.

AT: There is a highly visual quality to the novel, together with its musical one. The very organisation of language in space and time seems to generate color: "Everything is colored by movement. Even the space between words." (160) What is the relation between your painting and writing?

RS: I exhibited a series of drawings in the eighties called Systematic Drawings. They were executed via very specific instructions developed from musical scoring and cartography models. The outlines of numerous found images were fragmented and remapped according to elaborate alphanumeric charts. (Scores again!) By building up layers I created images that bore little resemblance to the original found images. It took me from four to six weeks to make one drawing using these methods. Other than that, I made a lot of free drawings and collages not based on any system other than whatever occurred to me when I was doing them.

When I came to Paris in 2008 and stayed in an unfinished studio, I felt the need to fill the physical space. Urgently. I bought art supplies and went at it for the duration of my time there. Since then, I have continued this at regular intervals. Mixed media work on paper mostly. It is intense, but a different kind of concentration than the sort I do when I play the piano or write. But the relationships in the way I think, make, and process materials cross over. It is a circuit for me now. I use a lot of paint, but have never once touched a brush. I apply paint with almost everything else, but not one brush stroke so far. There's something stubborn about that.

I work in software programs like Photoshop and Logic the same way. I tend to find a balance between precise organization and improvisation of various sorts. I set limits 
and I reconfigure for each project. I want to be surprised at how things come out. It keeps me very interested in what I'm doing.

Another way of answering this question is to say that the tensions between surface and depth, figure and ground, landscape and portrait, abstract and concrete images, are present in a very particular way when I work on mixed media constructions. These tensions get transmogrified into my writing unavoidably.

AT: Are you interested in narrative, in landscape, and how would you define your interest?

RS: The idea of landscape recurs literally and figuratively in Passes Through. The narrator is a field of voices. And I like the idea of seeing the narrator/narration as a portrait made up of landscape.

AT: Passes Through, as its title indicates, is all motion, transformations and transitions. What is the nature of your interest for the in-between?

RS: Being and knowing are completely related to movement. There is no memory without movement-constant incessant movement, the paradox being that the movement insures that memory is alive and ever changing: each moment rewrites the ephemeral quality of histories. Patterns and categories are attempts to make the chaos of existence bearable and useable. Passes Through has something to do with movement that produces a less goal-oriented state of mind, a state that resides between categories and subverts the usual patterns of telling.

AT: The workings of memory: to what use do you put them, from the creator's and the reader's points of view?

RS: Passes Through is as an experiment in memory. The text is the residue of a ninemonth long performance piece during which I carried out a specially designed threepronged system for culling and mixing material from more than a decade of my own journaling with tiny bits of other texts according to a schedule designed to challenge my short-term memory in various ways.

After labouring over Henri Bergson's Matière et Mémoire (Matter and Memory) and delighting in Frances Yates' histories of memory (including The Art of Memory), I did extensive research on how processes shift in the way we remake our memories depending on how much time has passed and how often the memories are recalled. I incorporated my findings into the scheduling of when and how I carried out my systems, systems that were partly translations of models I compiled from particular composers, ones that use radical approaches to the distribution of the sonic material in their pieces, not only Feldman, but John Cage (manically extensive chance operations) and Karlheinz Stockhausen (Moment Form) as well.

AT: How did you work on the representation of time through tenses and rhythms, including punctuation?

RS: Tenses shift and fluctuate in several ways during the course of Passes Through (rhythmically?). This movement creates a constant question about where in time the narrator is as saying occurs. As well, the shifting back and forth from present to past tense in a non-grammatically sound, but regular, basis pulls and pushes the speaking closer and farther from the narrator in a special sense. It creates a fluxing proximity in intimacy between the text and the reader. This works in tandem with an alternation of personal pronouns. 
This fluxing has spatial (sculptural) concerns. I spent some time learning how different cultures and societies have different limits of what is appropriate in personal space relations. How close or far you are when you speak to a friend versus a stranger is to some degree a matter of locally implied regulation. My interest in this influenced how I thought about how close and far the reader is from the narrator's voice (or voices really) at a given time.

Punctuation is a much different matter. Almost the only type of punctuation mark in Passes Through is a period. I could have used a dash of some sort, but I simply like periods. I like how they look: tiny filled-in circles of black. I was not so much considering the history of how the period has been used, as much as I was choosing a pleasing shape to mark a rest or pause in the text. My intentions time-wise in that regard are inexact. If I had wanted more precision in the pauses, I would have invented something along the lines of what Ursule Molinaro did by employing a series of spaces and varied punctuation marks to demark the exact length of pauses in some of her texts.

But since Passes Through was written for my voice and I don't read it exactly the same way every time, I didn't want to do that. Through my attentiveness to method I find ways to create freedoms, some quite unexpected.

Silence, gaps, holes, blanks, pauses in the flow of information are crucial for determining meaning. They increase the pressure on what is actually there making the noise. They allow for rhythmic patterns to emerge.

Rhythm in Passes Through exists in the conceptual ideas of how it is made as well as in the sound of the words. Patterns of sound and silence, movement to and fro in many senses and tenses are all part of an asymmetric micro and macro rhythmic scheme. My so-called regularities are not beat-oriented. Recurring patterns shift as they progress through time and move on top of each other.

\section{AT: Are you working on a new novel?}

RS: There are several things in progress. One of them is a novel about Germany. It has been in my mind in some form since the early nineties and I have been making the text object for about two years now. It is research oriented. I read in German every day.

This novel is not only being built in a different way, but as well will look very different from what I've done in the past. And as much as I enjoyed making Passes Through, I am relieved to be making something with such different subject matter.

I've also composed quite a lot of music for the ears over the last few years. And there is an inter-media piece I've been working on a long time. Versions of parts of it have been performed live. I continue making images using drawing and painting and software programs.

AT: How do you conceive of composition? Or what does this mean to you?

RS: Composition is a hobbyhorse, an open-ended process, an excursion, a tuning, a circuit, a probing, an overlaying, a reordering, a reframing, an act of translation.

Composition is a way of moving.

I make things to find out what they will become and what I will become via the making. 


\section{Passes Through: Extract}

4 I am lost inside a vast labyrinth of words and images. Black curving lines are spread unevenly across the concrete under my feet. My shoe bottoms leave ebony-mirrored blots in the shiny adhesive liquid. The intersecting loops and coils are similar to drawings that chart the complex paths subatomic particles take during contained reactions. There's a sliver of dirt between the concrete's rough edge and a lighter grayish concrete barrier. There is one pair of arrows spray-painted in orange on the barrier. They are the marks that workmen make before they dig up the streets. There's a long thin metal piece lying in the dirt. It has five unequal segments. Each is demarcated with a narrow band of white paint made from pulverized seashells. His eyes jerked back and forth under clenched lids. He had once been a knife that cut through anything. I accepted the rotten moods as part of his cycle of highs and lows and lower stills. Tulips. Wilted and mottled. Wrapped in marbled tissue. Out and out buffoonery. Unhappy accidents of character. Lemons and onions. Peeled, chopped, and burnt on an iron skillet. Crab claws. Stag horns. Pepper dots. Tangled hemp. Cloud heads. Splashed ink. Scandalous pranks. Veins in a lotus leaf. Eyes of polished obsidian. A conversation with long silences. New theories about tides. He took a ceramic mug from my kitchen cabinet and washed it with soapy water before using it. I wasn't prepared for contempt. He thought it okay to scorn the mediocre. No brain is as elastic as a child's before it's mired in dogma and intolerance. Some things sneak up on me. They emerge on my palette of desires. It becomes impossible to shut them out. There is a lessening, but nothing I do makes them go away. It makes me wonder if I can ever make contact with anyone here again. Maybe I never have. I find I can only touch the blurred edges where colors meet and become indistinct. There is an emptiness that lives with me in ambiguous locations. He fell asleep pressed against me. Mouth open. Pulling whatever stuck out into his dream. His hands crossed above his head as if they were tied there. I was wide-awake and dead to the world. He wore my shirt the whole weekend. I amused myself with eccentricities. He spent hours reading how charlatans deceived the credulous. Naming alter egos to express opposing viewpoints. Some pictures are never complete. They are constructed over the course of centuries by the combined efforts of a succession of thinkers. He traveled as much as possible. Trying to curry favor. Stopovers in luxurious hotels once frequented by wealthy artisans. In a lobby of jade and jasper he was captivated by a faded fresco of tilted triangles. Curly worms ate away at the integrity of straight edges. Upon closer inspection, he saw they were ravenous rows of numbers. Conventions once smeared on dusted planks returned by scratching wax or clay. Days later, on dewy hillsides he found these intricate ciphers coiled in the prayers and melodies of lonely shepherds. The tips of his fingernails were already black as he handed me a pewter snuffbox. He wanted to teach me how to grow rich from any mob's love of amusement. Some ravens have taught themselves how to bark. I told him I had settled for a few free copies of my words coming back at me in the mail. We parted early and I felt his best interests taunting me. I attended a poetry reading in a leaky art gallery. Dreary lifeless thoughts hitting the walls. Slapping a side of beef. The gallery owner went from person to person asking if they were poets. Doesn't everyone write poems? Not anymore. The state just runs around putting swords into the hands of madmen, while the peasants are self-helping themselves to death. Something about the weather. Sleet. Or snow and rain. Mixed. Squiggly lines 
organized into groups that transmit ideas from brain to brain. Drop wet spaghetti on the floor. It bounces all over the place. I like it when it means different things at different moments. Or even at the same time. Most people look for stabilizing markers. The four corners of every room. Completeness and permanence. Huh? They keep rearranging the same cages. He thought I was bored. He spent hours snubbing out-oftowners at parties. His insults were flawless. Quite correctly measured cubes of manure. Packed into the cheap compartments of vivid blue ice trays. Paint fumes made him sick. Time and tiredness modulated how I saw his colors. I deleted features that exhausted me. Afterimages lingered long enough to influence how I fabricated the next object. I filled history with fairy tales to make it more interesting. Steamed omasum and mushrooms braised in thin strips of ginger. He learned about color from watching rainbows and shining lights on the feathers of his birds. He wanted to get a dog to keep him company. I'd settle for a great many card games. Shuffling show-offs and moist cigars. Five little girls who dress like their mothers. Prose pregnant with hemistiches. Unintentional verse in a speech makes a bad impression. We fought over the shade of wall paint. Papaya with tapioca pearl. Nothing stabilized him. More pointless shrieks. The most brilliant reds were made from hard-shelled vermin. Hand-picked from columns of converted fish tanks. I liked him better when he was drunk. He came to life. I never knew whose. I couldn't afford the deep-end of his pool. The continual revulsion towards decent things. The total movement that comes from the death of routine. Here, an overture protrudes into the audience as novel architecture. Instruments lurching outward together in violent motions. Pulled by the conductor's hidden strings. I was jerking off when he called to apologize. He was perplexed and worried about my silence. I said I didn't have time to go with him to buy paint. I couldn't tell him I had abandoned color. I was setting up screens. Making a shape I had never seen to hide behind. I reorganized, cleaned, swept, threw out, only to realize later that I had concealed most of the tools necessary to continue.

INDEX

Thèmes : Reconnaissances

\section{AUTEUR}

ANNE-LAURE TISSUT

Université de Rouen 